\title{
A TEORIA GERAL DO GARANTISMO E A ESTRITA LEGALIDADE APLICADA A DIREITOS SOCIAIS: O EXEMPLO DA LEI 12.010/2009
}

\author{
LA TEORIA GENERAL DEL GARANTISMO Y LA ESTRITA LEGALIDAD \\ APLICADA A LOS DERECHOS SOCIALES: EL EXEMPLO DE LA LEY \\ $12.010 / 2009$
}

\author{
Francisco José Rodrigues de Oliveira Neto \\ UNIVALI - Universidade do Vale do Itajaí- Santa Catarina - Brasil
}

\begin{abstract}
RESUMO: Uma das transformações mais significativas que ocorreu no sistema jurídico brasileiro, diz respeito ao protagonismo judicial que ocorreu após a edição da Constituição de 1988. Tal questão tem sido objeto de um debate permanente que envolve, além das justificativas para esta atuação, os limites da mesma. Dentre as teorias que podem auxiliar e dar respostas efetivas a essa questão, está a Teoria Geral do Garantismo, a qual tem como espaço privilegiado de aplicação o Estado Constitucional de Direito e trás um conceito que se mostra fundamental no enfrentamento da questão relaciona ao ativismo judicial: a estrita legalidade que, em face da dupla artificialidade do sistema (formal e material), possibilita um controle mais democrático das políticas públicas. E foi justamente 0 que ocorreu com a edição da Lei 12.010/2009 a qual reformou parte do Estatuto da Criança e do Adolescente (lei 8069/90), reduzindo o espaço de discricionariedade judicial de forma adequada e positiva.
\end{abstract}

PALAVRAS-CHAVE: Ativismo Judicial. Direitos Sociais.Estado Constitucional de Direito. Garantismo. Lei 12.010/209.

\section{RESUMEN:}

Una de las transformaciones más significativas que ocurrió en el sistema jurídico brasileño, dice respecto al papel judicial que ocurrió después de la edición de la Constitución de 1988. Esta cuestión ha sido el tema de un debate permanente que implica, además de las justificativas para esta actuación, los límites de la misma. Entre las teorías que pueden auxiliar y dar respuestas efectivas a esa cuestión, está la Teoría General del Garantismo, que tiene como espacio privilegiado de aplicación el Estado Constitucional de Derecho e tras un concepto que se muestra fundamental en el enfrentamiento de la cuestión relacionada al activismo judicial: la estricta legalidad que, delante de la dupla artificialidad del sistema (formal y material), posibilita un controle más democrático de las políticas públicas. Y fue justamente lo que ocurrió con la edición de la Ley 12.010/2009, la cual reformó parte del Estatuto des Niño y del Adolescente (Ley 8.069/90), reduciendo el espacio de discreción judicial de forma adecuada y positiva. 
PALABRAS-CLAVE: Activismo Judicial. Derechos Sociales. Estado Constitucional de Derecho. Garantismo. Ley 12.010/209.

\section{CONSIDERAÇÕES INICIAIS}

Analisadas as transformações ocorridas no cenário jurídico nacional, uma das características mais marcantes é, sem dúvida alguma, o protagonismo judicial a partir da edição da Constituição da República em 1988. Defendido por alguns, criticado por outros, o fato é que em nenhum outro momento de nossa história republicana o Poder Judiciário esteve tão à frente do atendimento das políticas públicas incorporadas ao texto constitucional como hoje.

E é justamente daí que surge o debate sobre os limites da atuação jurisdicional, já que para alguns o poder de escolha do administrador público e do legislador não pode ser invadido pela atuação do Poder Judiciário. Para eles, tal quadro leva a um rompimento do princípio da separação de poderes, causando a substituição de um governo ou de um legislador democraticamente eleito, pela vontade de um agente político não legitimado para tanto. Já para outros, tal se mostra normal e aceitável em um Estado Democrático de Direito, cuja característica principal é a total submissão aos comandos colocados na Constituição, documento esse que tem a pretensão de dirigir todos os setores da vida em sociedade.

Outra questão importante que resulta dessa oposição de ideias a respeito dos limites da atuação dos Juízes está ligada a segurança jurídica, a qual - se adotada a tese que admite a inexistência de limites quando se trata da realização de direitos constitucionalmente assegurados - restaria comprometida ante a ausência de soluções uniformes para problemas comuns.

Partindo de uma visão negativa dessa atuação, o que se aclarará ao longo do texto, o objetivo aqui é demonstrar como é possível a utilização da Teoria Geral do Garantismo para fazer frente a esse protagonismo. Afinal, Luigi Ferrajoli - seu idealizador -sustenta uma concepção negativa do exercício do poder, combatendo claramente o autoritarismo na política e o decisionismo no Direito. Diz ele que no exercício do poder há sempre presente um potencial abuso, e sua 
neutralização somente ocorrerá de modo eficaz com a sustentação de uma visão instrumental do Direito e do Estado.

Disso decorre uma complexidade específica dos ordenamentos de constituição rígida: uma dupla artificialidade que não resulta somente do caráter positivo das normas produzidas - marca fundamental do positivismo jurídico -, mas também pela sua sujeição ao Direito - marca fundamental do Estado Constitucional de Direito. A produção jurídica está disciplinada por normas, tanto formais como substanciais, de direito positivo. Eis o resgate do princípio da legalidade, através da chamada "dupla artificialidade", que é um dos caminhos mais seguros para enfrentar essa difícil questão, a exemplo do que ocorreu com o direito penal, onde o princípio da legalidade (formal e material) tem sido utilizado com sucesso para evitar a permanente tentativa de endurecimento do sistema penal como resposta à criminalidade. Igual prática deveria e poderia ser adotada como os direitos sociais, onde há ainda um campo fértil para a busca de tais limites, a fim de que ajudem a justiça brasileira a encontrar parâmetros mais claros em relação à satisfação dessa modalidade de direitos.

$E$ foi especificamente o que ocorreu com o direito da criança e do adolescente, questão que se pretende explorar a seguir.

\section{A TEORIA GERAL DO GARANTISMO}

A partir da segunda metade do século XX, possível identificar duas transformações paralelas e semelhantes que se deram em campos diversos, mas que inegavelmente influenciaram não só o modo de compreensão do Direito, mas também as funções reservadas ao Estado contemporâneo. A primeira ocorreu na Filosofia do Direito, que admitiu a existência de um novo momento, o "póspositivismo", cuja essência reside no reconhecimento de que há um novo paradigma a merecer atenção, o paradigma constitucional, o qual tem como marca fundamental a superação do mero legalismo. A segunda ocorreu na Teoria do Estado. Nela, em lugar de um Estado de Direito e da centralidade do princípio da legalidade como norma de reconhecimento do Direito vigente, surge um Estado Constitucional de Direito, que se apresenta como superação do primeiro. A mudança reside na crescente importância das constituições contemporâneas, 
nelas destacadas duas características fundamentais: supremacia e rigidez. Esses documentos tornam-se os elementos centrais da nova formulação, que requer instrumentos aptos para a realização dos direitos fundamentais, categoria que se apresenta como elemento central desse novo momento.

A prática de declarar direitos em cartas constitucionais, ação iniciada com as revoluções liberais - especialmente a francesa no século XVIII, ganha força com esses movimentos. Nasce a esperança de que, transformadas as aspirações sociais em direitos fundamentais, e estes, por sua vez, colocados a salvo em Constituições protegidas das maiorias eventuais, ter-se-ia proteção suficiente para criar uma sociedade livre das barbáries ocorridas ao longo dos anos.

Constatou-se, porém, sua insuficiência, já que a dificuldade atual está localizada não mais no reconhecimento de direitos e na sua declaração, mas sim "em como juridicizar o Estado Social, como estabelecer ou inaugurar novas técnicas ou institutos processuais para garantir os direitos sociais básicos, a fim de fazê-los efetivos" (BONAVIDES, 2005, p. 338).

Tal é, sem dúvida alguma, o ponto fundamental para a superação final das antigas estruturas do Direito e do Estado - que ainda privilegiam antigas técnicas -, estruturas essas totalmente inadequadas para fazer frente a este novo desafio. O pensamento que proclama uma compreensão do sistema apenas e tão somente pela vinculação formal do conjunto normativo, já não tem mais lugar no pós-positivismo e no Estado Constitucional e Democrático de Direito.

Daí que cuidadoso exame merecem as ideias de Ferrajoli, expostas inicialmente em Diritto e Ragione, obra publicada na Itália em 1989 e traduzida para o espanhol em 1995. Desde então protagonista de grandes discussões, foi depois detalhada em uma série de trabalhos publicados, com especial atenção aos livros que apresentam os debates com outros professores, os quais serão analisados mais à frente.

A pretensão de Ferrajoli é construir uma "teoria geral do Garantismo", razão pela qual dedica os dois últimos capítulos de sua obra Direito e Razão a tratar do assunto. Na base de seu pensamento, há a identificação de três aspectos de uma crise profunda e crescente vivida pelo Direito na atualidade.

A primeira crise é a chamada "crise da legalidade", ou seja, do valor vinculante associado as regras pelos titulares dos poderes públicos, que se 
expressa pela ausência ou pela ineficácia dos instrumentos de controle. Seu resultado imediato é a ilegalidade do poder. Um reflexo dessa situação pode ser encontrado em vários Estados - europeus ou não - em que há uma espécie de Estado paralelo que funciona baseado na corrupção e se estende por todas as áreas (política, economia, administração pública etc.) (FERRAJOLI, 2001, p. 15).

A segunda está ligada à inadequação das estruturas do Estado de Direito para dar conta das novas funções a ele atribuídas no chamado Welfare State. Se antes a marca fundamental do modelo na sua versão liberal era a de protetor de uma esfera de individualidade, cuja atuação não exigia apenas a imposição de limites e proibições, agora tudo muda. Exige-se do Estado de Direito Social uma atuação positiva, atuante, pró-ativa, de que resulta uma inflação legislativa que é provocada pelos mais diversos setores sociais com leis cada vez mais específicas, parecendo meros atos administrativos. Há dificuldade para a consolidação de um sistema de garantias tão eficiente como foram aqueles criados para proteger os postulados do liberalismo, situação agravada pela acentuação do caráter incompleto, seletivo e desigual que se manifesta na crise pela qual este modelo de Estado passou no início dos anos setenta.

A terceira crise está relacionada ao debilitamento do Estado Nacional e se manifesta no deslocamento dos lugares da soberania, já que as questões relacionadas, por exemplo, às questões militares, de política monetária e políticas sociais escapam de suas fronteiras, passando a depender mais de questões externas do que de questões internas. Além disso, há um enfraquecimento do constitucionalismo, ante a inexistência de suporte teórico em Direito Internacional que resolva a inserção desses novos espaços decisórios externos no sistema das fontes de Direito.

No raciocínio de Ferrajoli, o problema central está em que essas três crises podem colocar em colapso a própria Democracia, já que, por trás de todas elas, está presente uma crise da legalidade, ou seja, do princípio da legalidade na sua versão mais pura e naquilo que tem de mais precioso: a vinculação de todos às normas legais. Sua ausência gera a ilegalidade do poder e formas neoabsolutistas de exercício do poder público "carentes de limites y de controles y gobernadas por interesses fuertes y ocultos, dentro de nuestros ordenamentos" (FERRAJOLI, 2001, p.17). 
A esse respeito pode ser dito ainda que - como se trata de uma teoria que se desenvolve no ambiente do Estado Constitucional de Direito e é própria dele não traz consigo a simples defesa de um mero legalismo, até porque 0 Garantismo é incompatível com a falta de limitação jurídica do poder legislativo, já que a mera sujeição do juiz à lei possibilitaria a convivência com as políticas mais autoritárias e antigarantistas (ABELLÁN, 2005, p. 21).

Sustenta sim, a partir de uma concepção negativa do exercício do poder, vez que reconhece que há sempre presente um potencial abuso, que sua neutralização somente ocorrerá de modo eficaz com a sustentação de uma visão instrumental do Direito e do Estado. O Garantismo se opõe de modo veemente "al autoritarismo en política y al decisionismo em derecho, propugnando, frente al primero, la Democracia sustancial y, frente al segundo, El principio de legalidad; en definitiva, El gobierno sub leges (mera legalidad) y per leges (estricta legalidad)" (ABELLÁN, 2005, p. 22).

Pensar o contrário colocaria em risco as conquistas do Estado Moderno, em especial, os direitos fundamentais, já que é inegável a perda de confiança que pode gerar, especialmente após a constatação das crises existentes que afetam diretamente o sistema normativo e, como já destacado, o princípio da legalidade. É bem verdade, afirma Ferrajoli, que, na época da implantação do sistema juspositivista, o quadro não era diferente, ou era até pior, mais complexo e irracional. Contudo, não se pode negar que a razão jurídica atual tem a seu favor um aliado importante: os progressos do constitucionalismo, que permitem configurar e construir o Direito atual - muito mais do que se permitiu no velho Estado Liberal - com um sistema artificial de garantias constitucionalmente preordenadas para a tutela dos direitos fundamentais (FERRAJOLI, 2001, p. 18).

Tal decorre de uma complexidade específica dos ordenamentos de constituição rígida: uma dupla artificialidade que não resulta somente do caráter positivo das normas produzidas - marca fundamental do positivismo jurídico -, mas também pela sua sujeição ao Direito - marca fundamental do Estado Constitucional de Direito. A produção jurídica está disciplinada por normas, tanto formais como substanciais, de direito positivo (FERRAJOLI, 2001, p. 19).

Nesse passo, Garantismo e Estado Constitucional de Direito são expressões que se identificam, podendo até mesmo afirmar-se que o segundo 
expressa a fórmula política do primeiro, de modo que, apenas por meio desse, aquele consegue realizar seu programa, até porque "solo este modelo político incorpora um riguroso 'principio de estrita legalidad', que supone el sometimiento del poder no únicamente a limites formales, sino también a los limites sustanciales impuestos por los principios y derechos fundamentales" (SANCHíS, 2005 p. 41).

Pois bem, voltando à mencionada "dupla artificialidade", é preciso dizer que ela se constitui na mais importante conquista do Direito contemporâneo, já que o modelo garantista se opõe frontalmente ao modelo paleopositivista, na medida em que se apresenta como uma garantia diante do Direito ilegítimo. Nessa construção, as Constituições são fundamentais, já que é na sua primazia como sistema de limites e vínculos para a maioria que deve ser reconhecida uma das suas dimensões essenciais, não menos importante que sua dimensão política. É o que Ferrajoli chama de dimensão substancial da Democracia, em contraposição à dimensão meramente formal, constituída precisamente pelo princípio da maioria.

Há, contudo, um aspecto importante que leva necessariamente ao reconhecimento da segunda dimensão, a substancial: no cerne da primeira, está localizada a confusão entre Democracia e princípio da maioria, de forma a se entender esta última apenas como o poder da maioria legitimado pelo voto popular. Tal compreensão

[...] ignora la que es la máxima adquisición y al mismo tiempo el fundamento del Estado constitucional de derecho: la extensión del principio de legalidad también al poder de la mayoría $y$, por consiguiente, la rígida sujeción a la ley de todos los poderes públicos, incluindo el legislativo, y su funcionalización a la tutela de los derechos fundamentales constitucionalmente garantizados (FERRAJOLI, 1995, p. 11).

Eis o reconhecimento de uma dimensão substancial da Democracia, com o importante detalhe de que estes vínculos materiais não são outra coisa senão as garantias dos direitos fundamentais, desde os direitos de liberdade até os direitos sociais:

[...] cuya estipulación ha introdocido, en la estructura misma del principio de legalidad propio del actual estado constitucional del derecho, una racionalidad sustancial que se ha añadido a la racionalidad formal propia del viejo positivismo jurídico y del paradigma roussoniano de la Democracia Política, basados ambos en la omnipotencia del legislador de mayoria (FERRAJOLI, 1995, p. 12). 
Partindo de uma base de Direito Penal, em que se visualiza com perfeição a divergência entre a normatividade do modelo constitucional e a ausência de efetividade nos níveis normativos inferiores, Ferrajoli sustenta a já referida "Teoria Geral do Garantismo". Como ele mesmo afirma:

La orientación que desde hace algún tiempo se conoce por el nombre
de 'Garantismo' nació en el campo penal como una réplica al creciente
desarrollo de la citada divergencia, asi como a las culturas jurídicas y
políticas que la han avalado, ocultado e alimentado, casi siempre en
nombre de la defensa del estado de derecho y del ordenamiento
democrático(FERRAJOLI, 1995 p. 851).

A partir daí, Ferrajoli propõe o significado da palavra "Garantismo" em três concepções diversas, suscetíveis de ser trasladadas para todos os campos do conhecimento jurídico.

A primeira delas decorre do entendimento de Garantismo como um modelo normativo de Direito, já que é justamente a partir do Direito Penal que a palavra representa a ideia de estrita legalidade, própria do Estado de Direito; a segunda representa a acepção do termo Garantismo como uma teoria jurídica da validez e da efetividade, consideradas categorias distintas entre si, e também da vigência ou existência das normas. Nesse caso, a palavra Garantismo expressa uma aproximação teórica que mantém separados o ser do dever ser do Direito, além de propor como questão central a divergência existente - nos ordenamentos complexos - entre:

modelos normativos (tendencialmente garantistas) y práticas operativas
(tendencialmente antigarantistas), interpretándola mediante la antinomia
- dentro de ciertos limites fisiológica y fuera de ellos patológica - que
subsiste entre validez (e inefitividad) de los primeros y efectividad (e
invalidez) de las segundas (FERRAJOLI, 1995, p. 85).

Por fim, na terceira forma de compreender Garantismo, a palavra designa uma filosofia política que impõe ao Direito e ao Estado uma "carga de la justificación externa conforme a los bienes y a los interesses cuya tutela y garantia constituye precisamente la finalidad de ambos" (FERRAJOLI, 1995, p. 853).

Ferrajoli explica ainda que esses três sentidos, que até aquele momento haviam sido usados com uma conotação unicamente relacionada ao Direito Penal, contêm um alcance teórico mais amplo e desenham uma teoria geral fundada nos seguintes aspectos: 1) caráter de vinculação do poder público no Estado de Direito; 2) divergência entre validade e vigência produzida pela 
existência de normas em níveis diversos dentro do sistema jurídico e certo grau (irredutível) de ilegitimidade jurídica das atividades normativas de níveis inferiores; 3) distinção entre ponto de vista externo (ou ético-político) e ponto de vista interno (ou jurídico) e daí a divergência entre justiça e validade; e, por fim, 4) autonomia e precedência da justiça e um certo grau de ilegitimidade política das instituições vigentes com relação a ela (FERRAJOLI, 1995, p. 854).

Por todos esses motivos, fica evidente que a ampliação do campo de incidência do Garantismo jurídico é perfeitamente possível, já que a similitude de questões a ser superadas do antigo Estado de Direito e a construção de estruturas para a plena vigência do Estado Constitucional de Direito, assim apontam. Some-se a isso a identidade estrutural entre os diversos sistemas presentes no ordenamento jurídico, elemento que torna possível a ampliação dessas estruturas para os mais diversos campos do Direito que, na atualidade, passam pelos mesmos problemas.

\section{AS MUDANÇAS PROVOCADAS PELA INTRODUÇÃO DO GARANTISMO JURÍDICO EM UM MODELO DE POSITIVISMO CLÁSSICO}

A apresentação das mudanças trazidas pelo novo modelo de Garantismo leva necessariamente a um confronto direto com a concepção de Direito sustentada pelo positivismo clássico, diferença essa que pode ser percebida nos seguintes planos: 1) no plano da Teoria do Direito, em que se faz necessária uma revisão da concepção de validade das normas jurídicas, que decorre da diferenciação que é feita entre validade e vigência; 2) no plano da teoria política, já que agora se postula o reconhecimento da dimensão substancial da Democracia, não sendo mais suficiente apenas sua compreensão no plano formal; 3) no plano da teoria da interpretação e da aplicação da lei, vez que agora se impõe ao juiz uma nova postura, com a redefinição do seu papel, e, ainda, das condições para que se dê sua vinculação; e, 4) no plano da ciência jurídica, que se afasta de uma postura meramente descritiva do sistema, para assumir uma postura crítica em relação ao seu objeto. 


\subsection{O Garantismo e a Teoria do Direito}

No que se refere à primeira alteração, evidencia-se uma clara superação das teses apresentadas por três dos mais importantes teóricos do Direito no século passado: Kelsen, Bobbio e Hart. Isto porque, conforme Ferrajoli, a validade da norma não é mais identificada unicamente por sua conformidade com as normas que regulam sua produção e que também pertencem a esse ordenamento (FERRAJOLI, 2001, p. 20).

Para o autor, essa concepção é uma simplificação indevida do sistema normativo e resulta da falta de compreensão da complexidade do princípio da legalidade no Estado Constitucional de Direito, já que não se pode desconhecer que neste, o sistema de normas sobre a produção de normas não se compõe unicamente de regras formais que tratam de competência ou procedimentos, mas sim - e também - traz "normas sustanciales, como el principio de igualdad y los derechos fundamentales, que de modo diverso limitan y vinculan al poder legislativo excluyendo o imponiéndole determinados contenidos" (FERRAJOLI, 2001, p. 21).

Isso significa que uma norma deixa de ser reconhecida somente pelo atendimento aos requisitos previstos para sua criação. Passa a exigir também respeito à matéria que é objeto dessa lei, que não poderá jamais contrariar o conteúdo da "norma de reconhecimento". Para os aspectos formais, há o conceito de vigência, que serve justamente para a verificação do respeito, ou não, aos procedimentos para a elaboração da norma, da competência para sua edição e do atendimento aos requisitos necessários para produzir seus efeitos. Para as questões relacionadas à sua substância, ao seu conteúdo, ao seu aspecto material, busca-se o conceito de validade, que é resultado direto da dupla artificialidade do sistema jurídico que hoje se reconhece.

Há uma imposição de limitação ao poder do legislador - já que na compreensão de Ferrajoli a possibilidade do abuso do poder está sempre presente - a qual é feita fundamentalmente através da separação dos conceitos de vigência e validade da norma, que deixam de ser compreendidos como um só, o que ocorria no estado paleopositivista de Direito. Agora uma norma será justa, 
se merecer a aprovação moral, juízo que é externo ao sistema; será válida, se não contiver vícios materiais, ou seja, não contrariar normas hierarquicamente superiores; será vigente, se preencher os requisitos formais previstos no sistema; e, por fim, será eficaz se observada pelos destinatários (ABELLÁN, 2005, p. 26).

Contudo, apesar das vantagens identificadas na teoria apresentada por Ferrajoli - considerada como uma completa Filosofia do Direito que inclui teses metodológicas, conceituais e axiológicas - ainda assim algumas dificuldades podem ser encontradas, especialmente no que se refere à separação entre vigência e validade. Nesse sentido, Abellán afirma que, ao se considerar a vigência como uma categoria submetida a um juízo interpretativo e não um mero juízo de fato, e a validade também como um juízo de interpretação e não de valor indecidível, em ambos os casos não há como se afastar de uma discricionariedade interpretativa, no segundo caso mais presente do que no primeiro (ABELLÁN, 2005, p. 33).

A consequência disso é que a validade se torna então um juízo externo, afirmação reforçada pela interpretação de Ferrajoli apresentada por Abellán, para quem:

interpretar la constituición no consiste solo en atribuir significado al texto normativo según el canon interpretativo de la intención de su autor, sino según la filosofia política que subyace a la misma y que esta solo imperfectamente recoge; es decir, según el modelo axiológico del Garantismo(ABELLÁN, 2005, p. 35).

Apesar de apontar que esse efeito pode levar ao enfraquecimento do Garantismo, vez que o coloca em posição próxima àqueles a quem critica, é preciso dizer que esse detalhe pode ser compreendido de outra forma.

É que - além de se tratar de um juízo interno e não externo - detém um forte componente de racionalidade sistêmica, ausente no exame da justiça da norma, uma vez que, como lembra Serrano:

el juicio de validez depende de los mecanismos internos de control del sistema jurídico, en mucha mayor medida que el juicio de justicia pueda depender de mecanismos de control de los sistemas Morales. Los sistemas jurídicos están más diferenciados y son, en este sentido, mucho más cerrados que los sistemas Morales(SERRANO, 1999, p. 53).

Ainda em relação ao entendimento de validade sustentado por Ferrajoli, tal sustentação leva ao reconhecimento de que - a partir daí - se constroem três novas esferas de decisão política, inexistentes na compreensão do sistema 
jurídico no modelo paleopositivista do Estado de Direito, em que validade e vigência se confundem. São elas: 1) a do indecidível formada pelo conjunto de direitos de liberdade e de autonomia que impedem decisões - expectativas negativas - que podem lesioná-los ou reduzi-los; 2) a do indecidível formada pelos direitos sociais que impõem decisões - expectativas positivas - dirigidas a satisfazê-los; e, por fim, 3) a do decidível, instância em que se legitima o direito de autonomia, tanto política (através da representação) como privada (através das regras do mercado). E é justamente nesse ponto, de acordocomSanchís:

[que a] Democracia formal aparece generada por los derechos de autonomia que determinan quién y cómo se manda; la Democracia sustancial viene delimitada por los derechos de liberdad que dan lugar a obligaciones de abstención o respeto de âmbitos de inmunidad (lo indecidible) y por lo derechos sociales que reclaman acciones positivas de dar o de hacer (lo indecidible que no) (SANCHíS, 2005 p. 43).

Dá-se então o ponto de encontro das duas formas de compreender 0 sistema, promovendo a ligação entre o aspecto formal e o substancial, com especial ênfase aos direitos fundamentais.

\subsection{O Garantismo e as Dimensões da Democracia (Formal e} Substancial)

$\mathrm{Na}$ relação entre Garantismo e Democracia, o que sobressai é a compreensão de um aspecto até então encoberto ou desconhecido da Democracia, que é a sua dimensão substancial, já que de um olhar para a Democracia que servia apenas para ditar procedimentos de coleta da vontade popular, passa-se a perceber a existência de outro aspecto em relação a ela, agora voltado para a garantia de direitos não só da maioria, mas também da minoria, vez que seu reconhecimento impede que a primeira anule ou aniquile os direitos da segunda, sem qualquer possibilidade de existência de uma onipotência da primeira, o que resulta de uma compreensão de Democracia plebiscitária ou majoritária.

E é justamente em oposição a essa compreensão limitada de Democracia que Ferrajoli aponta a existência de uma Democracia constitucional, a qual se contrapõe a uma Democracia legitimada unicamente pela vontade da maioria que 
desqualifica os limites impostos ao poder executivo, tido como um poder absoluto no modelo paleopositivista de Estado de Direito (FERRAJOLI, 2008, p. 25).

A esse pensamento se opõe a moderna concepção de Constituição, já que reduz (ou elimina) sua principal função por meio da imposição de limites ao poder. Para Ferrajoli, a essência do constitucionalismo e do Garantismo - e da Democracia constitucional

\begin{abstract}
reside precisamente en el conjunto de limites impuestos por las constituciones a todo poder, que postula en consecuencia una concepción de la Democracia como sistema frágil y complejo de separación y equilíbrio entre poderes, de limites de forma y de sustância a su ejercicio, de garantias de los derechos fundamentales, de técnicas de control y de reparación contra sus violaciones (FERRAJOLI, 2008, p. 27).
\end{abstract}

Nesse novo modelo, o Estado constitucional está submetido ao Direito, tanto quando os demais poderes do Estado, o que se dá em função da supremacia constitucional, elemento que se apresenta como uma das grandes novidades nos sistemas políticos do pós-guerra. Dá-se o surgimento de um novo paradigma que passa a informar todo o Direito, redefinindo sua função dentro do sistema social, o qual pode ser mais bem compreendido se observado que é a partir do fim da Segunda Guerra mundial - quando o homem percebe que sua capacidade de destruição é superior a sua capacidade de construção - que se dá o seu surgimento. É justamente ali que se veem os malefícios que podem ser causados pela maioria diante da ausência de limites a ela e, ainda, que o consenso das massas não pode ser a única fonte de legitimação do poder (FERRAJOLI, 2008, p.28). Há uma redescoberta das constituições com uma leitura mais ampla do artigo 16 da Declaração dos Direitos do Homem e do Cidadão de 1789, em que estava dito que só tinha Constituição a sociedade que garantisse direitos e separasse poderes.

A tudo isso se agrega um novo elemento: a rigidez constitucional, elemento que se apresenta com a concepção hierarquizada do sistema jurídico de onde decorre a supremacia do texto constitucional - e que resulta, conforme Ferrajoli:

en la sujeición al derecho de todos los poderes, incluso el poder legislativo, em el plano del derecho interno y también el del derecho internacional: su sujeición, precisamente, al imperativo de la paz y a los princípios de justicia positiva, y ante todo a los derechos fundamentales, establecidos tanto em las constituciones estatales como en ese embrión de constituición mundial constituido por la Carta de las Naciones Unidas 
y la Declaración universal de los derechos humanos (FERRAJOLI, 2008, p. 29).

Esse novo elemento faz com que o momento de elaboração de uma Constituição seja um momento especial, único. Com isso, retira-se da maioria o poder de supressão de direitos e garantias, e asseguram-se os direitos à minoria, o que autoriza a afirmação de que o Estado Constitucional é mais do que Estado de Direito, já que o elemento democrático nele introduzido não foi apenas ali colocado para travar o poder, foi também inserido pela necessidade de legitimação desse mesmo poder (CANOTILHO, 2003, p.100).

Há uma constitucionalização da ordem jurídica, que pode ser identificada com as chamadas "sete condições de constitucionalização" já mencionadas, que é preciso repetir: 1) rigidez constitucional, de modo que qualquer reforma do texto maior somente poderá se dar através de um processo mais agravado do que aquele utilizado para a aprovação, modificação ou revogação das leis ordinárias; 2) controle de constitucionalidade, decorrente da rigidez e da supremacia da Constituição, que funciona como mecanismo de proteção da autoridade do texto fundamental, ao prever modos de retirar do sistema o que lhe for contrário; 3) força vinculante da Constituição, já que não se pode admitir que um texto com essa importância deixe de gerar obrigação aos cidadãos e ao poder público, até porque "al asegurar el carácter normativo de las constituciones se garantiza la vinculación a las cláusulas constitucionales de los poderes públicos y los ciudadanos en los momentos de política ordinária" (PEÑA FREIRE, 2004, p. 34); 4) A adoção de uma interpretação extensiva da Constituição, ou seja, uma compreensão da Constituição de modo a extrair também as normas implícitas nela inseridas; 5) Aplicação direta das normas constitucionais, o que impõe a compreensão de que se trata de um documento que - em lugar de estar no topo do ordenamento jurídico - também pode ser visto no centro de uma estrutura de onde irradia toda sua força normativa; 6) Interpretação das leis ordinárias conforme a Constituição, o que significa levar a extremos o controle de constitucionalidade, incorporando as modernas técnicas de fiscalização da constitucionalidade das leis, alçando, inclusive, as variações de interpretação das normas fora do texto maior; e, por fim, 7) Influência da Constituição nas relações políticas, o que decorre diretamente da aceitação do documento perante a comunidade em geral (GUASTINI, 2005, p. 50-58). 
De todas as mencionadas, não há dúvida de que as duas primeiras são essenciais e fundamentais nesse processo, já que são justamente elas que determinam a colocação da Constituição em um novo espaço que a diferencia daquele que Ihe era reservado no antigo Estado Paleopositivista de Direito. Com isso, tem-se uma Constituição resultante da compreensão de que com ela esse espaço servirá como um elemento de superação da debilidade estrutural presente no antigo Estado de Direito.

Afirma-se o caráter jurídico e vinculante dos textos constitucionais, a rigidez e a qualificação de determinados referentes jurídicos, tais como os direitos fundamentais, signos desse processo (CADEMARTORI, 2006, p. 20).

Nesse passo, torna-se explícita a compreensão de que os direitos fundamentais constituem a base da igualdade moderna, igualdade em direitos que evidencia duas características estruturais que diferenciam essa categoria de direitos de todas as demais. A primeira pode ser percebida no direito de propriedade, este, um tipo de direito que pode ser chamado de universal, já que corresponde a todos na mesma medida, diferentemente do que ocorre com os direitos patrimoniais, que são direitos excludentes, posto que um sujeito pode ou não ser detentor, com um importante detalhe que deve ser levado em consideração: ao ser uma pessoa titular de um direito desse tipo, dá-se a exclusão dessa possibilidade para todas as demais. A segunda está relacionada à indisponibilidade e à inalienabilidade, tanto ativa como passiva, características que "los sustrae al mercado y a la decisión política, limitando la esfera de lo decidible de uno y otra, y vinculándola a sua tutela y satisfacción" (FERRAJOLI, 2001, p. 23).

Aqui também, evidentemente, estão presentes os elementos que sustentam um Estado Constitucional de Direito em superação ao velho Estado de Direito de matrix paleopositivista, já que essenciais se mostram duas de suas características já ressaltadas, a saber, a supremacia e a higidez do texto constitucional. Ocorre dessa forma pelo simples fato de que esses dois elementos colocam a salvo de toda e qualquer maioria eventual os direitos da minoria.

Adianta Ferrajoli que a dupla artificialidade - que determina a existência de normas que tratarão da vigência e de normas que tratarão da validade das 
normas - serve também para o reconhecimento de que a dimensão formal da Democracia estará atenta a quem decide e a como se dá a decisão política, ao passo que a dimensão substancial (ou material) está focada sobre o que pode ou não ser objeto da decisão política (FERRAJOLI, 2001, p. 23).

\subsection{O Garantismo e o Papel do Juiz}

Se na Teoria do Direito e na extensão de mais um significado ao entendimento do que é Democracia, os reflexos do Garantismo se fazem presentes, idêntica situação ocorre em relação à atividade jurisdicional e às possibilidades interpretativas que se abrem para o operador do Direito. Em verdade, e especialmente no que se refere ao primeiro ponto, há uma redefinição do papel que o juiz pode ocupar dentro do sistema, já que será a jurisdição uma função que dará a garantia ao cidadão de que a norma inválida e que não diga respeito aos parâmetros substanciais, deixará de ser aplicada por falta de vinculação. Com isso, a ilegitimidade do poder que a colocou no sistema ficará evidenciada, já que, no novo sistema, a vinculação do juiz não será mais à lei, como no velho Estado Paleopositivista de Direito. Agora, no Estado Constitucional de Direito, a vinculação se dá à Constituição, pois nela estão depositados os valores fundamentais da sociedade expostos sob o título de direitos fundamentais. Como explica Ferrajoli:

En esta sujeición del juez a la Constituición, y, en consecuencia, en su papel de garante de los derechos fundamentales constitucionalmente establecidos, está el principal fundamento actual de la legitimación de la jurisdición y de la independencia del poder judicial de los demás poderes, legislativo y ejecutivo, aunque sean - o precisamente porque son - poderes de mayoría.(FERRAJOLI, 2001, p. 26).

Disso decorre uma importante consequência que diz respeito ao fundamento do exercício da atividade jurisdicional, a partir do reconhecimento de que sua atribuição é a garantia de direitos fundamentais com o respeito à dupla artificialidade do sistema. Cai por terra o dogma de que sua legitimação está relacionada apenas e unicamente à separação de poderes. Há, como se vê, um deslocamento, de modo que:

Esta legitimación no tiene nada que ver com la de la Democracia Política, ligada a la representación. No se deriva de la voluntad de la mayoría, de la que asimismo la ley es expresión. Su fundamento es 
únicamente la intangibilidad de los derechos fundamentales (FERRAJOLI, 2001, p. 27).

O que se pode extrair disso é uma mudança fundamental que se dá com a alteração na concepção do Estado de Direito - e sua passagem para um Estado Constitucional de Direito - e a compreensão do Garantismo não mais como apenas uma mera proteção dos direitos de liberdade em relação ao Estado, ou diante dele, entendimento histórico da expressão. Se antes era assim entendido, o que gerava uma função jurisdicional típica do liberalismo calcada na ideia de separação dos poderes, agora a concepção de Garantismo representa uma forma de identificar a Democracia constitucional própria do Estado Constitucional de Direito (IBANHES, 2005, p. 61).

Isso explica sua raiz penal e a ampliação para a garantia de todos os demais direitos fundamentais, legitimando e justificando a atuação judicial para essa proteção - já que o sistema constitucional atual impõe de maneira vinculante uma Teoria Crítica do Direito, não mais limitada e na ocultação das divergências entre o ser e o dever ser, mas que problematiza o Direito, perdendo o juiz seu papel tradicional imposto pela visão kelseniana do ordenamento.

\subsection{O Garantismo e a Ciência Jurídica}

No que se refere à quarta e última das alterações produzidas no velho Estado de Direito em sua versão juspositivista, está ela relacionada à afirmação de que situações como a incoerência, a falta de plenitude, as antinomias e as lacunas são vícios insuperáveis do sistema jurídico. Na visão de Ferrajoli, tal situação - em lugar de alimentar um pessimismo em relação às possibilidades do Direito - no Estado Constitucional e Democrático de Direito, constituem-se em seu maior mérito. O que à primeira vista se mostra paradoxal, deixa de sê-lo ao se observar que justamente as características do Estado Democrático de Direito é que excluem as formas de legitimação absoluta e permitem sempre "más que la legitimación, la deslegitimación del ejercicio de los poderes públicos por violaciones $\mathrm{O}$ in cumplimientos de las promesas altas e difíciles formuladas en sus normas constitucionales" (FERRAJOLI, 2001, p. 28).

Diante disso, evidencia-se um papel destinado à ciência jurídica inexistente no antigo modelo, que é justamente o de exercer um papel crítico em 
relação ao seu objeto de estudo, e não apenas e tão somente descritivo. Com a já falada dupla artificialidade existente no sistema de normas jurídicas, surgem possibilidades dentro do sistema - e não mais de fora dele - de se promoverem as correções necessárias para impedir o abuso de poder manifestado pela inserção de normas que violem esse mesmo conjunto normativo, agora não unicamente pela forma de inserção, mas também pelo conteúdo.

Importante observar que esse papel crítico, que se dá no campo da legitimidade da norma, está ligado - também - ao seu conteúdo, a partir do exame da sua validade que, como já exposto, difere da vigência. A esse respeito, ainda é preciso destacar a questão relacionada à justiça da norma, que difere tanto da vigência quanto da validade.

Em relação ao primeiro, tal se evidencia pelo fato de que a vigência é apenas e tão somente relacionada à existência jurídica da norma, ou seja, é um juízo de fato que abre a possibilidade de observação dos aspectos meramente formais exigidos para que a norma possa fazer parte do ordenamento jurídico. Quanto ao segundo, as diferenças se mantêm, já que se trata de um juízo de adequação entre o conteúdo da norma e o conteúdo das normas superiores a ela. Contudo, há um ponto que merece destaque: aqui há uma identidade entre o juízo de justiça da norma e a sua validade, relacionada à estrutura do exame que é feito. Tais coincidências ocorrem em dois pontos: 1) juízos valorativos e 2) juízos complexos, difusos ou de grau, em oposição ao de vigência, que é simples ou binário (sim ou não), já que "establecer que uma norma jurídica deriva de otra o, cuando menos, que no e sin compatible com Ella no es uma operación geométrica o posibilística, sino una determinación probabilística de grados" (SERRANO, 1999, p. 52).

Em síntese, pode-se lembrar com Cademartori quando afirma que essa forma de compreender e abordar o Direito "coloca em questão dois dogmas do positivismo jurídico dogmático: a fidelidade do juiz à lei e a função meramente descritiva e avalorativa do jurista em relação ao direito positivo vigente" (CADEMARTORI, 2006, p.104). 


\title{
4. A TítULO DE CONSIDERAÇÕES FINAIS: A LEI 12.010/2009 COMO UM EXEMPLO DE APLICAÇÃO DA ESTRITA LEGALIDADE E A LIMITAÇÃO POSITIVA DA ATIVIDADE JURISDICIONAL
}

Quando o assunto é direitos sociais, um dos pontos mais sensíveis da Constituição da República é o que trata do direito das crianças e dos adolescentes e se evidencia na ênfase dada ao assunto, tratado em um capítulo inteiro da Constituição de 1988. Dos artigos que tratam da matéria, o principal é o de número 227, em que está dito:

\begin{abstract}
É dever da família, da sociedade e do Estado assegurar à criança e ao adolescente, com absoluta prioridade, o direito à vida, à saúde, à alimentação, à educação, ao lazer, à profissionalização, à cultura, à dignidade, ao respeito, à liberdade e à convivência familiar e comunitária, além de colocá-los a salvo de toda forma de negligência, discriminação, exploração, violência, crueldade e opressão.

Pela simples leitura desse artigo, percebe-se uma ênfase especial à chamada "política da proteção integral", expressão que resume a visão doutrinária adotada pelo sistema constitucional brasileiro, deixando para trás as formas antes privilegiadas que, ao longo dos anos, mostraram-se insuficientes para dar conta do problema, ainda mais violadoras do que garantidoras de direitos e, por isso mesmo, inadequadas como mecanismos de proteção às crianças e adolescentes.

Para compreender o alcance dessa mudança de paradigma, é preciso voltar ao início do século passado, quando o Brasil editou o Decreto $\mathrm{n}$. 17.943-A, de 12 de outubro de 1927, ato legislativo que modificou a situação de total descaso até então existente em relação aos menores. Esse documento, na época considerado um avanço, olhado com a distância do tempo, mostra-se insuficiente, já que trata a criança e o adolescente de forma única, desconsiderando as diferenças entre as duas fases do crescimento, o que se percebe ao observar que todos eram tratados de forma geral como "menores abandonados" e, a partir daí, colocados na condição de "filhos do Governo".
\end{abstract}

Alguns dispositivos são interessantes e bem demonstram a visão equivocada, como é o caso do art. 15 que preconizava: "A admissão dos expostos á assistencia se fará por consignação directa, excluido o systema das rodas". Essa norma possibilitava a entrega da criança para o Estado sem a identificação da genitora, de forma anônima. Admitir essa condição significa tratar a criança como um objeto à disposição do adulto, sem levar em consideração a existência de seu direito à convivência familiar.

Outro exemplo está no art. 26 do já mencionado Decreto que considerava como abandonados e colocava sob a tutela do Estado, não só aqueles que tinham menos de 18 anos sem habitação certa ou meios de subsistência por serem os pais falecidos ou desaparecidos, como também os "que se encontrem 
em estado habitual de vadiagem, mendicidade ou libertinagem" mesmo que seus pais fossem conhecidos(inciso $V$, do art. 26, do Decreto n. 17.943-A, de 12.10.1927).

Como se vê, para situações completamente diversas, era o mesmo o tratamento previsto. Caso houvesse o reconhecimento da criança e do adolescente como sujeitos de direito, seria outra a intervenção proposta.

Essa compreensão equivocada manteve-se nas legislações posteriores, dentre as quais merece destaque o Código de Menores de 1979, que adota a chamada "Doutrina da Situação Irregular" e afirma em seu artigo $1^{\circ}$ que aquele código tratava da "assistência, proteção e vigilância a menores". O mencionado código descreve no art. $2^{\circ}$ o que entende por menor em "situação irregular": aquele que estivesse em falta, omissão ou impossibilidade dos pais; fosse vítima de maus tratos; corresse perigo moral; estivesse em desvio de conduta ou fosse autor de infração penal. Mais uma vez, em lugar da individualização, o trato genérico exclusivamente focado no adulto.

Com o já mencionado art. 227 da Constituição de 1988 e a adoção da política de proteção integral, muda-se por completo essa concepção que traz como marca: 1) a compreensão de que a violação de qualquer direito da criança ou do adolescente é de responsabilidade da família, da sociedade ou do Estado; 2) desaparecem as caracterizações ambíguas como "risco", "perigo moral", "situação irregular" que nelas permitiam o enquadramento de qualquer situação fora do padrão ditado pelos adultos; 3) as crianças e os adolescentes são sujeitos de direitos, e não mais meros problemas ou objetos à disposição dos adultos; e, por fim, 4) há uma forte atenção à garantia dos direitos, não se preocupando o legislador apenas com sua declaração.

Dentro dessa linha foi editado o Estatuto da Criança e do Adolescente (Lei n. 8069/90), ato normativo que tem por pretensão detalhar toda a "política da proteção integral" - como anuncia já nos seus primeiros artigos - e o faz a partir de uma estrutura dividida em três sistemas de garantias: em primeiro, as políticas públicas de atendimento (arts. $4^{\mathrm{a}}$ a 87 ); em segundo, as medidas de proteção destinadas às crianças e aos adolescentes em situação de violação de seus direitos (arts. 98 a 101); e, por fim, um sistema que trata de medidas sócioeducativas aplicáveis a adolescentes em conflito com a lei. Os demais 
dispositivos tratam das estruturas que darão suporte a este sistema de garantias, como os Conselhos, a Justiça da Infância e da Juventude, as infrações administrativas e os crimes específicos, bem como suas penalidades.

De início, uma das características que pode ser percebida no trato do direito da infância e da juventude no Direito brasileiro é que, de uma concepção que nominalmente era protetiva, mas na prática era seletiva, já que deixava aos aplicadores da norma um largo espaço para, inclusive, escolher quem deveria se enquadrar nos seus conceitos, caminhou-se para a adoção de uma legislação que identificava melhor os casos que a ela deveriam se submeter, abandonando as denominações ambíguas e o espaço de escolha do aplicador da norma.

Agora, embora evidente a escolha desse caminho, há ainda um largo espaço de discricionariedade deixado ao aplicador da norma (seja na esfera administrativa, seja na esfera jurisdicional) quando se trata da implementação de qualquer dos direitos ali previstos. O que se vê é que, na aplicação concreta desses dispositivos, ainda persistem inúmeras possibilidades de interpretação, a exemplo, registre-se, do que ocorreu com a distribuição de remédios nos casos de portadores do HIV (vírus da imunodeficiência humana) e doentes de AIDS (Síndrome da Imunodeficiência Adquirida).

É bem verdade que, com a edição da Lei n. 9313/96 (que determina a distribuição gratuita de medicamentos), houve uma redução das decisões judiciais contraditórias, caminhando-se para uma uniformização. Mas é preciso recordar o que ocorria antes dela: de um lado, decisões determinando a concessão do remédio de forma gratuita a toda e qualquer pessoa que dele necessitasse; ao mesmo tempo, de outro, decisões negando essa possibilidade pelos mais diversos argumentos, os quais iam desde a falta de estrutura do Estado para atender a todos, até julgamentos morais relacionados aos portadores da referida síndrome.

É inegável que parte do problema foi resolvida, mas também é inegável que em muitas outras situações ele persiste, o que se dá pela existência de um ponto comum entre eles: a existência de "vazios" legislativos que possibilitam arbítrios jurisdicionais e tratamento desigual a situações semelhantes. Tanto isso é verdade que, na tentativa de resolver esse problema, o Conselho Nacional de Justiça editou a Recomendação n. 31, de 30 de março de 2010, documento que 
apresenta várias medidas que devem merecer a atenção do juiz quando se depara com pedidos dessa natureza, tudo com o objetivo de evitar decisões conflitantes que importem em gastos inadequados ao Estado, seja com medicamentos ainda em fase experimental, seja com medicamentos de eficácia duvidosa ou destinados a pessoas em condições de arcar com seus custos.

É justamente aqui que se aplicaria a noção da estrita legalidade, agora redimensionada em face da dupla artificialidade proclamada por Ferrajoli, ou seja, em face do vínculo formal e do vínculo substancial, sempre tendo por parâmetro a Constituição Federal e a possibilidade de uso dos seus instrumentos de defesa, em especial, o controle de constitucionalidade.

A exemplo do que já ocorre com o Direito Penal, abre-se a possibilidade de construção de um sistema garantista de ordem social mais claro e aplicável com maior facilidade, evitando a contaminação de concepções pessoais, que estariam impedidas de invadir a esfera de atuação judicial como forma de limitar o exercício dos direitos fundamentais. Além disso, obrigaria de modo mais claro o administrador a implementar tais direitos.

Retomando o caso do direito da criança e do adolescente, foi justamente isso que ocorreu com a edição da Lei 12.010, de 03 de agosto de 2009, com o objetivo de aperfeiçoar a sistemática prevista para garantia do direito à convivência familiar a todas as crianças e adolescentes. Pela leitura dos seus diversos artigos, que promovem alterações substanciais no Estatuto da Criança e do Adolescente, o que se percebe não é uma mudança de concepção no trato da matéria como antes colocada, mas sim uma especificação dos institutos previstos, detalhando-os de modo mais claro, não só em relação aos procedimentos que devem ser adotados, mas também em relação às condições para a ocorrência de uma série de situações jurídicas.

Exemplo disso é o que diz agora o art. 19, § 20. "A permanência da criança e do adolescente em programa de acolhimento institucional não se prolongará por mais de 2 (dois) anos, salvo comprovada necessidade que atenda ao seu superior interesse, devidamente fundamentada pela autoridade judiciária". Antes dele, não havia qualquer prazo fixado para a busca de uma solução, abrindo-se um grande espaço de liberdade ao juiz para a escolha do destino a ser dado à criança naquela situação, sem qualquer justificativa. Isso agora não será mais 
possível diante da obrigatoriedade de justificar quando o prazo previsto for superado.

Outro ponto que igualmente demonstra a opção pelo detalhamento em lei com o objetivo de evitar manifestações contraditórias é o que trata da habilitação para adotar. Desde a edição do Estatuto da Criança e do Adolescente (Lei n. 8069/1990), foi implantado na maioria dos juizados da infância e juventude espalhados pelo Brasil um sistema que dispunha que toda adoção deveria ser antecedida por uma habilitação prévia. Esta era feita por meio de um pedido assinado pelos próprios requerentes, em que, além de apresentar as características da criança ou adolescente por eles desejado, anexavam alguns documentos. Depois, os pretendentes eram submetidos a um estudo social e, com manifestação do Ministério Público, era prolatada uma decisão judicial declarando-os habilitados, ou não, ato que poderia merecer recurso à instância superior.

A lei determina os cuidados referentes à adoção em artigo específico em que se lê:

Art. 50. A autoridade judiciária manterá, em cada comarca ou foro regional, um registro de crianças e adolescentes em condições de serem adotados e outro de pessoas interessadas na adoção.

$\S 1^{\circ} \mathrm{O}$ deferimento da inscrição dar-se-á após prévia consulta aos órgãos técnicos do Juizado, ouvido o Ministério Público.

$\S 2^{\circ}$ Não será deferida a inscrição se o interessado não satisfizer os requisitos legais, ou verificada qualquer das hipóteses previstas no art. 29.

Percebeu-se, no entanto, que, em inúmeras comarcas espalhadas pelo Brasil, tal procedimento era limitado à simples colocação do nome do interessado em um livro após contato com as assistentes sociais, o que era feito sem qualquer formalidade maior que permitisse conhecer mais o pretendente e, após isso, elaborar um juízo seguro sobre sua preparação para a responsabilidade de assumir uma criança ou adolescente.

A falta de uniformidade no proceder levou à necessária regulamentação de modo mais detalhado daquilo que antes já era a intenção do legislador, ou seja, uma avaliação preliminar do pretendente a fim de dar maior segurança às novas adoções. Para tanto, o legislador detalhou de modo mais claro o procedimento a ser seguido, reduzindo a possibilidade de dispensa do procedimento. 
É o que se vê nos parágrafos e incisos incluídos no art. 50, da Lei 8069/90 a partir da Lei n. 12010/2009, merecendo destaque a obrigatoriedade de "preparação psicossocial e jurídica", agora prevista no novo parágrafo $3^{\circ}$, do art. 50, o que torna explícita a intenção da habilitação: preparar as pessoas para a adoção. É ali que está colocado:

A inscrição de postulantes à adoção será precedida de um período de preparação psicossocial e jurídica, orientado pela equipe técnica da Justiça da Infância e da Juventude, preferencialmente com apoio dos técnicos responsáveis pela execução da política municipal de garantia do direito à convivência familiar.

Além disso, o novo parágrafo $4^{\circ}$ também trata e regulamenta algo que na prática já ocorre, mas que precisa ser organizado, o contato dos pretendentes com as crianças e adolescentes disponíveis para adoção:

\begin{abstract}
Sempre que possível e recomendável, a preparação referida no $\S 3^{\circ}$ deste artigo incluirá o contato com crianças e adolescentes em acolhimento familiar ou institucional em condições de serem adotados, a ser realizado sob a orientação, supervisão e avaliação da equipe técnica da Justiça da Infância e da Juventude, com apoio dos técnicos responsáveis pelo programa de acolhimento e pela execução da política municipal de garantia do direito à convivência familiar.
\end{abstract}

Com isso, evitam-se situações indesejáveis como, por exemplo, o contato com todas as crianças, inclusive aquelas não disponíveis para adoção, o que pode gerar sofrimento desnecessário aos pretendentes e às crianças, já que caso haja interesse na adoção - essa seja obstada pela existência de vínculos com os genitores. Com a visita e o contato orientados, os encontros se darão somente com as crianças e adolescentes em condições de adoção.

Idêntica é a situação quando se trata do deferimento do pedido de adoção. Na redação anterior do Estatuto da Criança e do Adolescente, não havia qualquer menção expressa de que a adoção deveria ser deferida apenas a pessoas previamente habilitadas no cadastro de adoção. Havia a previsão desse cadastro em apenas dois artigos e nada mais. Tal situação gerou uma grande divisão na doutrina e na jurisprudência, havendo quem afirmasse a obrigatoriedade da inscrição prévia, ao lado de outros que afirmavam ser ela desnecessária e mera formalidade. Com isso, admitiam-se adoções que, na maioria dos casos, acobertavam transações comerciais.

Com a nova lei, a situação aclarou-se. O parágrafo 13 do art. 50 afirma: 
Somente poderá ser deferida adoção em favor de candidato domiciliado no Brasil não cadastrado previamente nos termos desta Lei quando:

I - se tratar de pedido de adoção unilateral;

II - for formulada por parente com o qual a criança ou adolescente mantenha vínculos de afinidade e afetividade;

III - quando oriundo o pedido de quem detém a tutela ou guarda legal de criança maior de 3 (três) anos ou adolescente, desde que o lapso de tempo de convivência comprove a fixação de laços de afinidade e afetividade, e não seja constatada a ocorrência de má-fé ou qualquer das situações previstas nos arts. 237 ou 238 desta Lei.

Com esse dispositivo, mais uma vez, limita-se a liberdade do julgador, de modo a obrigá-lo a seguir um critério mais claro, e menos pessoal, no deferimento das adoções, tornando explícita a necessidade de que o cadastro seja a principal opção para a aproximação de crianças e adolescentes e pretendentes, colocando a adoção direta (ou pronta) - aquela em que as pessoas já comparecem ao juizado com a criança ou adolescente que pretendem adotar como uma exceção limitada à hipótese prevista no inciso III. Isso evita o comércio, a intermediação indevida e a exploração que poderá daí decorrer. Garante o direito à convivência familiar, já que é possível um trabalho com a família biológica para a recolocação da criança ou adolescente entre seus membros, além de aumentar as possibilidades de sucesso da adoção por força da preparação anterior já tratada, fundamental para evitar as devoluções.

Estes exemplos demonstram como é possível tornar a atividade jurisdicional mais democrática e menos pessoal, privilegiando a compreensão de que o fato de ser instrumento para a garantia de direitos fundamentais ou de agente político não autoriza qualquer agente do Estado a se arvorar em detentor de uma legitimidade inexistente em um sistema político em que a busca do equilíbrio no exercício do poder é uma das marcas fundamentais.

Evidentemente que haverá casos em que a estrita legalidade não será suficiente. Contudo, não se pode esquecer que hoje temos um sistema de controle de constitucionalidade bem desenhado, com imposição de respeito aos limites formais e materiais ditados pela Constituição, o que, por certo, contribuirá para impedir abusos legislativos ou, ainda, abusos nas decisões judiciais. 


\section{REFERÊNCIAS}

ABELLÁN, Marina Gascón. La teoría general del garantismo: rasgos principales. In: FERRAJOLI, Luigi.Garantismo -Estudios sobre el pensamiento jurídico. Edição de Miguel Carbonell y Pedro Salazar. Madrid: Trotta, 2005.

BONAVIDES, Paulo. Curso de Direito Constitucional. $17^{\underline{a}}$ ed. São Paulo: Malheiros, 2005.

CADEMARTORI, Sérgio. Estado de Direito e Legitimidade. $2^{a}$ ed. Campinas: Millennium Editora, 2006.

CANOTILHO J. J. Gomes. Direito Constitucional e Teoria da Constituição. $7^{a}$ ed. Coimbra: Almedina, 2003.

FERRAJOLI, Luigi. Derecho y razón, Madrid: Ed. Trotta, 1995.

. Derechos y garantias. La ley del más débil. Tradução de IBÁÑES, Andrés Perfecto y GREPPI, Andrea. $2^{\underline{a}}$ ed. Madrid, Espanha: Editorial Trotta, 2001.

. MORESO Juan José; ATIENZA, Manuel. La teoria del derecho en el paradigma constitucional. Madrid: Fundación Colóquio Jurídico Europeo, 2008.

. Garantismo y Democracia. Org. de Miguel Carbonell. Madrid: Trotta, 2008.

GUASTINI Ricardo. La constitucionalización del ordenamiento jurídico: el caso italiano. In: Neoconstitucionalismo(s). CARBONELL Miguel (edición). $2^{\underline{a}}$ ed. Madrid: Ed. Trotta, 2005.

IBANHES, Perfecto Andrés. La teoría general del Garantismo: rasgos principales. In: FERRAJOLI, Luigi.Garantismo - Estudios sobre el pensamiento jurídico. Edición de Miguel Carbonell y Pedro Salazar. Madrid: Editorial Trotta, 2005. 
SANCHÍS, Luis Prieto. Constitucionalismo y Garantismo. In: Garantismo Estudios sobre el pensamiento jurídico de Luigi Ferrajoli. Org. de Miguel Carbonell y Pedro Salazar. Madrid: Editorial Trotta, 2005.

SERRANO, José Luis. Validez y vigência. Madrid: Trotta, 1999.

PEÑA FREIRE, Antonio Manoel. Constitucionalismo Garantista y Democracia. In:

Crítica Jurídica: Revista Latinoamericana de política, filosofia y derecho n. 22, Curitiba: UNIBRASIL, 2004, p. 34. 